\title{
BIORREMEDIAÇÃO DE SOLO CONTAMINADO POR ÓLEO VEGETAL UTILIZANDO A BIOAUMENTAÇÃO COM Bacillus subtilis
}

\author{
Ana Carolina Correia de Oliveira ${ }^{1}$, Fábio Fernando de Araújo² \\ 1- Acadêmico do curso de Engenharia Ambiental. 2- Eng. Agrônomo, Doutor, Prof. do curso de Engenharia Ambiental, Universidade do
} Oeste Paulista (UNOESTE), Rod. Raposo Tavares, Km 572, 19067-175, Presidente Prudente, SP.

\section{RESUMO}

O aumento dos resíduos gerados e descartados inadequadamente no ambiente gera um impacto negativo em diversas áreas. O tempo de recuperação do local degradado é muito alto, por isso, faz-se necessário a utilização de alguma técnica que acelere o processo. Uma das melhores técnicas é a Biorremediação, que se utiliza de microorganismos, fungos, algas, plantas ou suas enzimas para degradar ou fixar os poluentes de maneira que eliminam sua periculosidade, ou ao menos a minimizem. $O$ presente trabalho objetivou avaliar a técnica da Bioaumentação em solo contaminados com óleo vegetal, acondicionados em 40 vasos em casa de vegetação, onde foram introduzidas duas estirpes de B. subtilis (AP-3 e A3-5) multiplicadas em laboratório. Foram realizadas coletas de amostras de solo periodicamente para monitorar a concentração de óleo presente no solo e avaliar as atividades enzimáticas proporcionada pelos microorganismos como também a massa fresca produzida pelas plantas.

Palavras-chave: Poluição; remediação; microorganismo.

\section{Bioremediation of soil contaminated by vegetable oil using bioaugmentation with Bacillus subtilis}

\begin{abstract}
The increase in waste generated and disposed of improperly in the environment generates a negative impact in several areas. The recovery time of the site is degraded very high, so it is necessary to use some technique to speed up the process. One of the best techniques is Bioremediation, which uses microorganisms, fungi, algae, plants or their enzymes to degrade pollutants or freeze in a manner that eliminates the danger, or at least minimize. This study aimed to evaluate the technique of bioaugmentation in soil contaminated with vegetable oil, packed in 40 pots in a greenhouse, where they were introduced two strains of $B$. subtilis (AP-3 and A3-5) multiplied in the laboratory. Were collected from soil samples periodically to monitor the concentration of oil in the soil and to evaluate the enzymatic activities offered by the microorganisms as well as the fresh weight produced by plants.
\end{abstract}

Key words: Pollution; remediation; microorganism. 


\section{INTRODUÇÃO E JUSTIFICATIVA}

A formação do solo, denominada de gênese, é lenta e gradual e depende basicamente do intemperismo que pode ser físico e/ou químico e/ou biológico (BAIRD, 2002). Tal formação tem influência do relevo, material de origem (rocha mãe), microorganismos existentes no solo, clima e tempo.

Apesar de o solo levar milhares de anos para se estruturar, através da intervenção humana basta pouco tempo para que ele perca o seu equilíbrio natural, podendo trazer graves consequências em todos os âmbitos, pois o solo não é um fim em si mesmo, ele faz parte de um ecossistema, e a sua desestabilização desencadeia uma série de alterações em todo o meio ambiente (MOTA, 1997).

Com o crescimento desenfreado da população e seu consumo excessivo, tem-se como resultado o aumento dos resíduos gerados por elas e a interferência em ambientes naturais para garantir as necessidades da mesma. Por muito tempo houve uma disposição inadequada dos resíduos gerados, inclusive os perigosos, sem nenhuma preocupação ambiental, ocasionando alta poluição do solo e de todo ecossistema (BRAGA et al., 2002).

Entende-se por poluição qualquer alteração no meio pela introdução de resíduos de forma acidental, planejada ou natural que cause contaminação. Tal degradação pode trazer consequências drásticas em todo o sistema, que é composto pela atmosfera, água e solo, dos quais são essenciais para a vida (MOTA, 1997). Para reverter, ou ao menos, minimizar os impactos causados no meio se faz necessário a utilização de algumas técnicas que acelerem sua recomposição, já que o tempo natural de regeneração do solo é extremamente alto.

A escolha da melhor técnica remediadora depende das características do passivo, o tempo de recomposição desejado e o respectivo custo-benefício. Uma das técnicas mais recomendadas para remediação é o tratamento biológico, pois se utiliza de organismos naturais ou seus componentes, que promovem um tratamento adequado ao meio e um baixo custo se comparado a outras técnicas.

O tratamento biológico denomina-se biorremediação e possui algumas formas diferentes de tratamento que se diferenciam pelo agente remediador utilizado (BAIRD, 2002). Os processos empregam microorganismos, fungos, algas verdes ou suas enzimas que ao utilizarem substratos orgânicos ou inorgânicos dos compostos poluidores, transformam os complexos em moléculas simples, ou então as armazenam evitando sua mobilidade.

\section{OBJETIVO}

O objetivo desse trabalho foi de avaliar a técnica de bioaumentação utilizando Bacillus subtilis como forma de remediar um solo contaminado por diferentes concentrações de óleo vegetal.

\section{METODOLOGIA}

O experimento foi conduzido durante os meses de Fevereiro à Novembro de 2009 na UNOESTE, Presidente Prudente, SP. Coletou-se solo de horta comercial (Unoeste), os quais foram acondicionados em 40 vasos $(2 \mathrm{~kg})$ em casa de vegetação. Para contaminação do solo utilizou-se óleo de soja de uso doméstico. A introdução de óleo vegetal no solo foi realizada em concentrações crescentes, de $0 \%$ (2 kg de solo+ 0,0 de óleo), $05 \%$ (1,9 $\mathrm{kg}$ de solo $+0,1 \mathrm{~kg}$ de óleo), $10 \%(1,8 \mathrm{~kg}$ de solo $+0,2 \mathrm{~kg}$ de óleo) e $15 \%$ (1,7 $\mathrm{kg}$ de solo $+0,3 \mathrm{~kg}$ de óleo).

Multiplicou-se em laboratório duas estirpes de $B$. subtilis. Para isto, foi preparado o caldo nutriente $(1,5 \mathrm{~g}$ de Extrato de Levedura e $2,5 \mathrm{~g}$ de Peptona) para crescimento dos isolados AP-3 e A3-5 de B. subtilis. Colocaram-se os 
erlenmeyers no agitador orbital deixando por 3 dias sob agitação. Após este processo, as bactérias foram diluidas em tubos de ensaio com água destilada para concentração final de $1.10^{8}$ bactérias por $\mathrm{mL}$ e assim as mesmas foram introduzidas no solo contaminado e em solo sem contaminação.

O experimento foi conduzido no esquema fatorial com 4 doses de óleo, dois microrganismo e quatro repetições. Como forma de avaliar o impacto causado pela contaminação do solo, foi utilizada alface como planta indicadora em todos os vasos. 0 desenvolvimento das plantas nos solos com diferentes concentrações de óleo e de microorganismos serviu como referência para mensuração do impacto causado. Desta forma após a introdução dos microrganismos no solo foi plantado uma muda de alface com 28 dias de idade em cada vaso. A alface foi cultivada três vezes em períodos de 40 dias. Após cada período as plantas eram coletadas e pesadas.

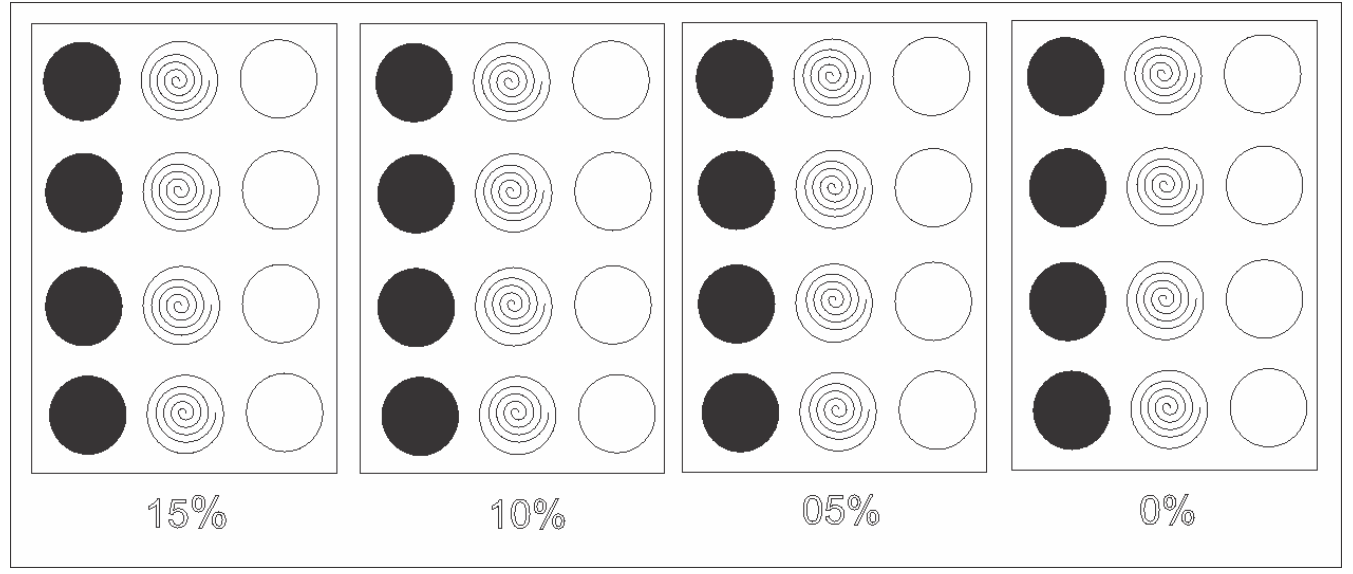

FIGURA 1 - Croqui do Experimento

Presença apenas de microorganismos autóctones

Inoculação da bactéria $B$. subtilis AP-3

Inoculação da bactéria $B$. subtilis A3-5

Periodicamente foram realizadas análises de gordura no solo em cada tratamento, tendo como base as Normas Analíticas do Instituto Adolfo Lutz (2008), através do Extrato etéreo - Extração direta em Soxhlet, para que se pudesse analisar se houve alteração na concentração de óleo. Para avaliar o metabolismo microbiano no decorrer do tempo e nos diferentes tratamentos foram feitas análises enzimáticas no solo segundo Van Os e Ginkel (2001) com o uso da técnica do trifeniltetrazólio e leitura em espectofotômetro a 530nm.
Os dados obtidos foram analisados estatisticamente pelo programa sisvar e as médias foram comparadas pelo teste ScottKnott.

\section{RESULTADOS}

Após a introdução das bactérias, fez-se a primeira, segunda e terceira coleta de solo e das plantas em 100, 140 e 200 dias, respectivamente. As amostras serviram para análise de óleo, umidade e atividade enzimática dos microorganismos. 
Os valores apresentados nas tabelas são médias aritméticas de cada tipo de solo, já que cada tipo estava acondicionado em 3 vasos com uma planta bioindicadora em cada um.

TABELA 1 - Teores percentuais de extrato etéreo no solo após 100 dias da inoculação de $B$. subtilis em solo com diferentes contaminações de óleo e cultivo da alface (coleta 1)

\begin{tabular}{ccccc}
\hline Tratamentos & \multicolumn{4}{c}{ Concentração de óleo adiconada ao solo } \\
\hline Controle & $0 \%$ & $5 \%$ & $10 \%$ & $15 \%$ \\
B. subtilis (A3-5) & 1,571 a1 & $1,893 \mathrm{a} 1$ & $3,075 \mathrm{a} 1$ & $4,450 \mathrm{a} 2$ \\
B. subtilis (AP-3) & $0,871 \mathrm{a} 1$ & $2,333 \mathrm{a} 1$ & $4,550 \mathrm{a} 1$ & $2,500 \mathrm{a} 1$ \\
& $0,224 \mathrm{a} 1$ & $1,600 \mathrm{a} 1$ & $3,820 \mathrm{a} 1$ & $5,322 \mathrm{a} 2$ \\
\hline
\end{tabular}

Médias seguidas de mesma letra na coluna não diferem estatisticamente a $5 \%$

Fonte: A autora

TABELA 2 - Teores percentuais de extrato etéreo no solo após 140 dias da inoculação de B. subtilis em solo com diferentes contaminações de óleo e cultivo da alface (coleta 2)

Tratamentos Concentração de óleo adiconada ao solo

\begin{tabular}{ccccc}
\hline & $0 \%$ & $5 \%$ & $10 \%$ & $15 \%$ \\
Controle & $0,250 \mathrm{a} 1$ & $1,450 \mathrm{a} 1$ & $1,175 \mathrm{a} 1$ & $2,150 \mathrm{a} 1$ \\
B. subtilis (A3-5) & $0,275 \mathrm{a} 1$ & $1,250 \mathrm{a} 1$ & $1,898 \mathrm{a} 1$ & $1,800 \mathrm{a} 1$ \\
B. subtilis (AP-3) & $0,450 \mathrm{a} 1$ & $0,700 \mathrm{a} 1$ & $2,475 \mathrm{a} 1$ & $3,950 \mathrm{a} 2$ \\
\hline
\end{tabular}

Médias seguidas de mesma letra na coluna não diferem estatisticamente a $5 \%$

Fonte: A autora

TABELA 3 - Teores percentuais de extrato etéreo no solo após 200 dias da inoculação de B. subtilis em solo com diferentes contaminações de óleo e cultivo da alface (coleta 3)

\begin{tabular}{ccccc}
\hline Tratamentos & \multicolumn{4}{c}{ Concentração de óleo adiconada ao solo } \\
\hline Controle & $0 \%$ & $5 \%$ & $10 \%$ & $15 \%$ \\
B. subtilis (A3-5) & $0,050 \mathrm{a} 1$ & $1,225 \mathrm{a} 2$ & $0,525 \mathrm{a} 1$ & $0,650 \mathrm{a} 1$ \\
B. subtilis (AP-3) & $0,050 \mathrm{a} 1$ & $0,450 \mathrm{a} 1$ & $0,375 \mathrm{a} 1$ & $1,525 \mathrm{a} 2$ \\
& $0,175 \mathrm{a} 1$ & $0,374 \mathrm{a} 1$ & $0,625 \mathrm{a} 1$ & $2,516 \mathrm{a} 3$ \\
\hline
\end{tabular}

Médias seguidas de mesma letra na coluna não diferem estatisticamente a $5 \%$

Fonte: A autora

TABELA 4 - Biomassa da parte aérea de alface após 100 dias da inoculação de $B$. subtilis em solo com diferentes contaminações de óleo (coleta 1 )

Médias seguidas de mesma letra na coluna não diferem estatisticamente a $5 \%$

Fonte: A autora

TABELA 5 - Biomassa das plantas após 140 dias da inoculação de B. subtilis em solo com diferentes contaminações de óleo (coleta 2) 


\begin{tabular}{ccccc}
\hline \multirow{2}{*}{ Tratamentos } & \multicolumn{4}{c}{ Concentração de óleo adiconada ao solo } \\
\cline { 2 - 5 } & Biomassa $(\mathrm{g})$ & Biomassa $(\mathrm{g})$ & Biomassa $(\mathrm{g})$ & Biomassa $(\mathrm{g})$ \\
\cline { 2 - 5 } Controle & $33,150 \mathrm{a} 2$ & $1,610 \mathrm{a} 1$ & $0,782 \mathrm{a} 1$ & $0,225 \mathrm{a} 1$ \\
B. subtilis (A3-5) & $29,525 \mathrm{a} 2$ & $1,240 \mathrm{a} 1$ & $0,302 \mathrm{a} 1$ & $0,297 \mathrm{a} 1$ \\
B. subtilis (AP-3) & $23,030 \mathrm{a} 1$ & $1,630 \mathrm{a} 1$ & $0,385 \mathrm{a} 1$ & 0,532 a1 \\
\hline
\end{tabular}

Médias seguidas de mesma letra na coluna não diferem estatisticamente a 5\%

Fonte: A autora

TABELA 6 - Biomassa das plantas após 200 dias da inoculação de B. subtilis em solo com diferentes contaminações de óleo (coleta 3)

\begin{tabular}{ccccc}
\hline \multirow{2}{*}{ Tratamentos } & \multicolumn{4}{c}{ Concentração de óleo adiconada ao solo } \\
\cline { 2 - 5 } & Biomassa(g) & Biomassa $(\mathrm{g})$ & Biomassa $(\mathrm{g})$ & Biomassa $(\mathrm{g})$ \\
\cline { 2 - 4 } Controle & $15,887 \mathrm{a} 2$ & $3,227 \mathrm{a} 1$ & $2,200 \mathrm{a} 1$ & $2,257 \mathrm{a} 1$ \\
B. subtilis (A3-5) & $12,290 \mathrm{a} 1$ & $2,752 \mathrm{a} 1$ & $1,635 \mathrm{a} 1$ & $1,245 \mathrm{a} 1$ \\
B. subtilis (AP-3) & $13,822 \mathrm{a} 1$ & $1,450 \mathrm{a} 1$ & $2,250 \mathrm{a} 1$ & $1,030 \mathrm{a} 1$ \\
\hline
\end{tabular}

Médias seguidas de mesma letra na coluna não diferem estatisticamente a $5 \%$

Fonte: A autora

TABELA 7 - Análise de atividade microbiana pela avaliação enzimática (desidrogenase) no solo após 100 dias da inoculação de $B$. subtilis em solo com diferentes contaminações de óleo e cultivo da alface (coleta 1). Leitura em espectrofotômetro (570 nm)

\begin{tabular}{ccccc}
\hline Tratamentos & \multicolumn{4}{c}{ Concentração de óleo adiconada ao solo } \\
\hline Controle & $0 \%$ & $5 \%$ & $10 \%$ & $15 \%$ \\
B. subtilis (A3-5) & $0,516 \mathrm{a} 1$ & $0,080 \mathrm{a} 1$ & $0,021 \mathrm{a} 1$ & $0,013 \mathrm{a} 1$ \\
B. subtilis (AP-3) & $0,605 \mathrm{a} 2$ & $0,092 \mathrm{a} 1$ & $0,033 \mathrm{a} 1$ & $0,019 \mathrm{a} 1$ \\
\end{tabular}

Médias seguidas de mesma letra na coluna não diferem estatisticamente a 5\%

Fonte: A autora

TABELA 8 - Análise de atividade microbiana pela avaliação enzimática (desidrogenase) no solo após 140 dias da inoculação de $B$. subtilis em solo com diferentes contaminações de óleo e cultivo da alface (coleta 2). Leitura em espectrofotômetro $(570 \mathrm{~nm})$

\begin{tabular}{ccccc}
\hline Tratamentos & \multicolumn{4}{c}{ Concentração de óleo adiconada ao solo } \\
\hline Controle & $0 \%$ & $5 \%$ & $10 \%$ & $15 \%$ \\
B. subtilis (A3-5) & 0,7191 a1 & $0,744 \mathrm{a} 3$ & $0,166 \mathrm{a} 2$ & $0,077 \mathrm{a} 1$ \\
B. subtilis (AP-3) & $0,842 \mathrm{a} 2$ & $0,503 \mathrm{a} 2$ & $0,073 \mathrm{a} 1$ & $0,069 \mathrm{a} 1$ \\
\hline
\end{tabular}

Médias seguidas de mesma letra na coluna não diferem estatisticamente a 5\%

Fonte: A autora

TABELA 9 - Análise de atividade microbiana pela avaliação enzimática (desidrogenase) no solo após 200 dias da inoculação de $B$. subtilis em solo com diferentes contaminações de óleo e cultivo da alface (coleta 3$)$. Leitura em espectrofotômetro $(570 \mathrm{~nm})$ 


\begin{tabular}{ccccc}
\hline Tratamentos & \multicolumn{4}{c}{ Concentração de óleo adiconada ao solo } \\
\hline Controle & $0 \%$ & $5 \%$ & $10 \%$ & $15 \%$ \\
B. subtilis (A3-5) & $1,070^{1}$ a1 & $0,787 \mathrm{a} 2$ & $0,505 \mathrm{a} 2$ & $0,547 \mathrm{a} 1$ \\
B. subtilis (AP-3) & $1,169 \mathrm{a} 1$ & $0,689 \mathrm{a} 2$ & $0,433 \mathrm{a} 2$ & $0,426 \mathrm{a} 1$ \\
\hline
\end{tabular}

Médias seguidas de mesma letra na coluna não diferem estatisticamente a $5 \%$

Fonte: A autora

\section{DISCUSSÃO}

Através de análise de atividade microbiana no solo pelo método da enzima desidrogenase, foi possível observar que os solos que continham maior concentração de óleo, apresentaram menor atividade enzimática, mesmo os inoculados com as bactérias.

A medida que aumentava a concentração de óleo no solo diminuía a massa das plantas porém, com o passar do tempo, foi verificado pela análise de extrato etéreo no solo que ocorreu a degradação do óleo, proporcionado pelos microrganismos autóctones do solo, já que as concentrações de óleo diminuíram até mesmo nos solos que não tiveram introdução de microorganismos selecionados.

\section{REFERÊNCIAS}

BRAGA, B. et al. Introdução à engenharia ambiental. São Paulo: Prentice Hall, 2002. p. 145-150.

BAIRD, C. Química Ambiental. 2.ed. Porto Alegre: Bookman, 2002. 622 p.

INSTITUTO ADOLFO LUTZ. Métodos FísicoQuímicos para Análise de Alimentos. 4.ed. 1.ed. Digital. São Paulo, 2008. Disponível em:

$<$ http://www.ial.sp.gov.br/index.php?option=co $\mathrm{m}$ _remository\&Itemid $=0 \&$ func $=$ select\&orderby $=1>$. Acesso em: 05 fev. 2009 .

MOTA, S. Introdução à Engenharia

Ambiental. 1.ed. Rio de Janeiro: ABES, 1997.

\section{CONCLUSÃO}

A técnica da bioaumentação com Bacillus subtilis não conseguiu incrementar a redução dos teores de extrato etéreo no solo contaminado com diferentes doses de óleo vegetal. A biorremediação passiva foi suficiente para redução dos teores de extrato etéreo no solo ao longo do período de condução do experimento e a utilização de alface como planta indicadora refletiu a contento a situação de contaminação do solo mostrando que a mesma pode ser utilizada como planta indicadora em área impactada com óleo.

VAN OS, G. J.; VAN GINKEL, J. H.

Suppression of Pythium root rot in bulbous Iris in relation to biomass and activity of the soil microflora. Soil Biol. Biochem., v. 33, p. 1447-1454, 2001. http://dx.doi.org/10.1016/S00380717(01)00053-0 